\title{
PERSEPSI DAN SIKAP MASYARAKAT TERHADAP KONSERVASI EKOSISTEM MANGROVE DI PULAU TANAKEKE SULAWESI SELATAN
}

(Perception and Attitude of Community Towards Mangrove Ecosystem Conservation at Tanakeke Island - South Sulawesi)

\author{
Heru Setiawan ${ }^{1}$, Rini Purwanti ${ }^{1}$, R. Garsetiasih ${ }^{2}$ \\ ${ }^{1}$ Balai Penelitian dan Pengembangan Lingkungan Hidup dan Kehutanan Makassar, Jalan Perintis Kemerdekaan \\ Km 16,5 Makassar, Sulawesi Selatan, Indonesia \\ E-mail: hieros81@gmail.com; rnpurwanti_up@yahoo.co.id \\ ${ }^{2}$ Pusat Penelitian dan Pengembangan Hutan, Jl. Gunung Batu No. 5, Bogor, Jawa Barat, Indonesia \\ E-mail: garsetiasih@yahoo.com
}

Diterima 31 Januari 2017, direvisi 27 Maret 2017, disetujui 29 Maret 2017

\begin{abstract}
People's perception and attitude towards mangrove conservation determine the success of mangrove rehabilitation. This study examines the level of people's perception and attitude toward mangrove conservation at Tanakeke Island. Data collection was conducted by field observation, interview, questionnaire and study literature. The overall number of respondents was 124 people spread proportionally according to the number of family in each village. The level of perception and attitude were obtained by using scoring techniques and factors that influence the level of perception and attitude, then were analyzed by using multiple linear regression. The results showed that based on the community perception, mangrove forests can provide variety of benefit to support their life, both ecology and economically. Level of people's perception was included in the medium category with $41.1 \%$ respondents, $40.3 \%$ at lower category and higher category with $18.5 \%$. Levels of public attitudes were dominated at low level by $65.3 \%$ respondents, medium category with $25.8 \%$ and high category with $8.9 \%$. There were three independent variables that significantly influence the level of public perception on mangrove conservation, namely residence location (villages), education level and participation in mangrove rehabilitation. Independent factor that significantly influence the level of people's attitudes, namely participation in mangrove rehabilitation.
\end{abstract}

Keywords: Mangrove conservation; people perception; people attitude; Tanakeke Island, South Sulawesi.

\begin{abstract}
ABSTRAK
Persepsi dan sikap masyarakat terhadap konservasi mangrove sangat menentukan keberhasilan kegiatan rehabilitasi mangrove. Penelitian ini bertujuan untuk mengetahui tingkat persepsi dan sikap masyarakat terhadap konservasi ekosistem mangrove di Pulau Tanakeke. Pengumpulan data dilakukan dengan observasi lapangan, wawancara, kuesioner dan studi pustaka. Jumlah responden secara keseluruhan adalah 124 orang yang tersebar secara proporsional sesuai dengan jumlah keluarga pada masing-masing desa. Tingkat persepsi dan sikap diperoleh dengan menggunakan teknik skoring dan faktor-faktor yang mempengarui tingkat persepsi dan sikap dianalisis dengan menggunakan analisis statistik regresi linear berganda. Hasil penelitian menunjukkan masyarakat Pulau Tanakeke memiliki persepsi bahwa hutan mangrove dapat memberikan berbagai manfaat bagi kehidupannya, baik secara ekologi maupun ekonomi. Secara umum tingkat persepsi masyarakat Pulau Tanakeke terhadap konservasi mangrove termasuk dalam kategori sedang yaitu $41,1 \%$, kategori rendah $40,3 \%$ dan kategori tinggi $18,5 \%$. Tingkat sikap masyarakat didominasi tingkat rendah dengan $65,3 \%$, tingkat sedang $25,8 \%$ dan tingkat tinggi $8,9 \%$. Terdapat tiga variabel independen yang berpengaruh signifikan terhadap tingkat persepsi masyarakat terhadap konservasi mangrove, yaitu tempat tinggal responden, tingkat pendidikan dan keikutsertaan responden dalam kegiatan rehabilitasi mangrove. Terdapat satu faktor independen yang berpengaruh signifikan terhadap tingkat sikap masyarakat, yaitu keikutsertaan pada kegiatan rehabilitasi mangrove.
\end{abstract}

Kata kunci: Konservasi mangrove; persepsi masyarakat; sikap masyarakat; Pulau Tanakeke, Sulawesi Selatan. 


\section{PENDAHULUAN}

Mangrove adalah berbagai jenis vegetasi dari tingkat sedang hingga tinggi dan semaksemak yang tumbuh di sepanjang daerah pasang surut atau daerah muara sungai di daerah tropis dan sub-tropis antara garis lintang $30^{\circ} \mathrm{N}$ dan $30^{\circ} \mathrm{S}$ (Giri et al., 2011). Ekosistem mangrove merupakan salah satu tipe ekosistem yang banyak dimanfaatkan masyarakat pesisir dalam menunjang kehidupannya, baik secara langsung (tangible) maupun tidak langsung (intangible). Hutan mangrove telah terbukti dapat memberikan berbagai manfaat ekonomi dan cadangan makanan bagi masyarakat lokal (Uddin et al., 2013). Nilai ekonomi yang diberikan mangrove di Brazil mencapai US\$12,500/ha/th yang didapatkan dari pemanfaatan ekowisata dan perikanan (Souza and Augusto, 2011). Nilai ekonomi total dari manfaat langsung, manfaat tidak langsung, manfaat keberadaan dan manfaat pilihan kawasan mangrove di Desa Tawiri, Kota Ambon sebesar Rp7.165.012/ ha/tahun (Soukotta, 2013) dan di Desa Passo, Kota Ambon sebesar Rp6.665.220/ha/tahun (Talakua, 2013).

Fungsi hutan mangrove di wilayah pesisir bukan hanya penting sebagai pelindung fisik, tetapi juga sebagai bagian terintegrasi dari eksositem wilayah pesisir lainnya, seperti ekosistem terumbu karang dan ekosistem padang lamun (Pontoh, 2011). Keberadaan hutan mangrove dapat memberikan berbagai manfaat, di antaranya ialah sebagai stabilitator kondisi pantai, mencegah terjadinya abrasi dan intrusi air laut, sebagai sumber keanekaragaman biota akuatik dan nonakuatik, sebagai sumber bahan yang dapat dikonsumsi masyarakat dan lain sebagainya (Yuliasamaya et al., 2014). Bagi masyarakat pesisir, ekosistem mangrove berperan penting dalam menopang kehidupan mereka, baik dari aspek ekonomi maupun ekologi. Pada aspek ekonomi, mangrove digunakan untuk arang, kayu bakar, alat tangkap ikan tradisional (paropo), dan tempat penangkapan berbagai jenis ikan, udang dan kepiting, sedangkan dari segi ekologis, ekosistem mangrove berfungsi sebagai penghasil bahan pelapukan (decomposer) yang merupakan sumber makanan penting untuk invertebrata kecil pemakan bahan pelapukan (detritus). Selanjutnya, mangrove juga berperan sebagai makanan bagi hewan yang lebih besar. Ekosistem mangrove juga merupakan daerah asuhan (nursery ground) bagi ikan dan kerang-kerangan (Hussain and Badola, 2010).

Hutan mangrove tersebar hampir di seluruh wilayah pesisir di Indonesia, mulai dari Sumatera, Jawa, Kalimantan, Sulawesi sampai ke Papua. Luasnya sangat bervariasi bergantung pada kondisi fisik, komposisi substrat, kondisi hidrologi, dan iklim yang terdapat di pulau-pulau tersebut. Luas hutan mangrove di Indonesia adalah yang terluas di dunia yang mencapai 3.112.989 ha, atau $22,6 \%$ dari total luasan mangrove di seluruh dunia (Giri et al., 2011). Provinsi Sulawesi Selatan dengan panjang garis pantai mencapai $1.937 \mathrm{~km}$ dan jumlah pulau 299 buah, merupakan habitat yang potensial bagi tumbuh dan berkembangnya ekosistem mangrove. Berdasarkan data dari Dinas Kehutanan Provinsi Sulawesi Selatan tahun 2014, luas mangrove di Provinsi Sulawesi Selatan mencapai 28.954,3 ha. Dari luasan tersebut hanya 5.238 ha $(18 \%)$ yang masih dalam kategori baik, sedangkan sisanya dalam kondisi rusak dan sangat rusak.

Salah satu ekosistem mangrove di Provinsi Sulawesi Selatan berada di Pulau Tanakeke, Kabupaten Takalar yang merupakan kawasan mangrove terluas di provinsi tersebut dengan luas mencapai 951,11 ha (Akbar, 2014). Kondisi ekosistem mangrove di Pulau Tanakeke telah mengalami degradasi yang cukup tinggi. Pada tahun 1970-an luas mangrove di Pulau Tanakeke mencapai 2.500 ha, kemudian pada periode 1990-an turun menjadi 1.300 ha, dan pada saat ini hanya 950 ha. Degradasi hutan mangrove ini tidak hanya terjadi di Pulau Tanakeke, dalam 
kurun waktu 40 tahun terakhir, tutupan lahan mangrove di seluruh dunia berkurang lebih dari setengahnya (Beys-da-Silva et al., 2014). Laju deforestasi yang terjadi pada hutan mangrove empat kali lebih besar daripada laju deforestasi pada hutan hujan tropis terrestrial (Blanco et al., 2012). Penyusutan luas hutan mangrove yang sangat cepat ini disebabkan meningkatnya populasi penduduk di wilayah pesisir, perubahan iklim, alih fungsi lahan untuk kegiatan pembangunan wilayah pantai, serta kegiatan pertanian dan perikanan (Ushakiranmai and Rajasekhar, 2015). Eksploitasi mangrove untuk kayu bakar dan arang juga menjadi salah satu penyebab terjadinya degradasi mangrove. Pengambilan kayu bakar sebanyak 1,079 $\mathrm{m}^{3}$ di Kabupaten Cilacap menyebabkan penyusutan luas hutan mangrove sekitar $26,551 \mathrm{~m}^{2}$ dan pengambilan kayu bakar sebanyak $0,782 \mathrm{~m}^{3}$ menyebabkan penyusutan luas mangrove sekitar 19,250 $\mathrm{m}^{2}$ (Tumisem dan Suwarno, 2008).

Berbagai upaya konservasi ekosistem mangrove di Pulau Tanakeke terus dilakukan oleh pemerintah maupun lembaga nonpemerintah. Beberapa diantaranya adalah dengan membentuk kelompok peduli mangrove, melakukan kegiatan rehabilitasi kawasan tambak yang telah rusak dan menginisiasi terbentuknya peraturan desa tentang perlindungan mangrove. Namun seringkali upaya konservasi tersebut mengalami kendala karena ketidaksamaan persepsi dan sikap masyarakat terhadap upaya konservasi mangrove tersebut. Untuk mencegah terjadinya kegagalan yang sama, maka persepsi masyarakat terhadap konservasi ekosistem mangrove di Pulau Tanakeke menjadi suatu hal yang perlu diketahui, sebab persepsi merupakan suatu dasar dari pembentukan sikap atau perilaku.

Persepsi secara umum sering diartikan sebagai cara pandang masyarakat atau seseorang terhadap suatu obyek, baik itu obyek fisik maupun sosial. Menurut Pahlevi (2007), persepsi adalah suatu proses untuk membuat penilaian (judgment) atau membangun kesan (impression) mengenai berbagai macam hal yang terdapat di dalam lapangan penginderaan seseorang. Sikap adalah kesiapan, kesediaan untuk bereaksi terhadap suatu objek, jadi masih berupa kecenderungan dalam bertindak demi seseorang (Rahayu, 2010). Sikap sangat menentukan perilaku dan tanggapan seseorang terhadap masalah kemasyarakatan serta masalah lingkungan.

Persepsi dan sikap masyarakat Pulau Tanakeke terhadap ekosistem mangrove akan memengaruhi dukungannya terhadap keberhasilan upaya konservasi mangrove. Persepsi dan sikap masyarakat sangat terkait dengan berhasil dan tidaknya, atau positif negatifnya perilaku masyarakat dalam mendukung upaya pelestarian ekosistem mangrove di Pulau Tanakeke. Sumber daya di alam tidak dapat dilestarikan dan dikelola dengan baik tanpa terlebih dahulu mengetahui persepsi dan sikap masyarakat terhadap lingkungan (Lee and Zhang, 2008). Dengan mengetahui persepsi dan sikap masyarakat terhadap sumber daya alam maka akan lebih mudah untuk merancang strategi konservasi dan manajemen yang efektif untuk menjaga agar sumber daya alam tetap lestari dan dapat memenuhi kebutuhan hidup masyarakat setempat (Dolisca et al., 2007). Jika seluruh sikap dan perilaku yang dilakukan masyarakat adalah negatif, maka dukungan terhadap upaya konservasi mangrove akan rendah. Persepsi yang positif dari masyarakat merupakan faktor penting yang menentukan kelestarian ekosistem mangrove di Pulau Tanakeke. Oleh karena itu penilaian terhadap persepsi dan sikap sangat penting dilakukan untuk menunjang keberhasilan kegiatan konservasi mangrove di Pulau Tanakeke.

\section{METODE PENELITIAN}

\section{A. Tempat dan Waktu}

Kegiatan penelitian ini dilakukan pada Bulan Juli sampai dengan November 2015 di Pulau Tanakeke, Kecamatan Mappakasunggu, Kabupaten Takalar, Provinsi Sulawesi 
Selatan. Pulau ini terletak di sisi barat daya daratan Provinsi Sulawesi Selatan dan berhadapan langsung dengan perairan Selat Makassar. Secara geografis, pulau ini terletak pada $119^{\circ} 14^{\prime} 22^{\prime \prime}-119^{\circ} 20^{\prime} 29^{\prime \prime}$ BT dan 5'26’43”- 5’32'34" LS. Secara administratif, Pulau Tanakeke terdiri dari lima desa, yaitu Desa Maccini Baji, Desa Balandatu, Desa Tompotana, Desa Rewatayya dan Desa Mattiro Baji.

\section{B. Bahan dan Alat Penelitian}

Bahan yang digunakan sebagai obyek kajian adalah masyarakat pesisir yang tinggal dan menetap di Pulau Tanakeke. Bahan pendukung penelitian diantaranya adalah peta tematik Pulau Tanakeke dan data sekunder yang terdiri atas data monografi desa dan data statistik terkait lokasi penelitian yang diperoleh dari beberapa instansi di Kabupaten Takalar. Alat yang digunakan antara lain daftar panduan pertanyaan, kuesioner, alat perekam, alat tulis, kompas dan kamera. Alat yang digunakan dalam proses pengolahan data adalah seperangkat komputer dengan perangkat lunak Microsoft Office 2007 (Word, Excel) and SPSS 19 untuk analisis statistik.

\section{Metode Pengambilan Data}

Penelitian ini menggunakan pendekatan kuantitatif, yaitu salah satu pendekatan penelitian yang lebih mengutamakan kajian empiris untuk mengumpulkan, menganalisis, dan menampilkan data dalam bentuk numerik. Metode pengambilan sampel dilakukan dengan teknik simple random sampling, dengan unit analisis yang digunakan adalah rumah tangga. Kepala rumah tangga dipilih sebagai responden yang mewakili rumah tangga di lima desa yang berada di Pulau Tanakeke. Jumlah keluarga di lokasi penelitian adalah adalah 1.558 keluarga. Penentuan jumlah responden dilakukan berdasarkan formula (Sugiyono, 2009).

Keterangan:

$$
S=\frac{N \cdot P \cdot Q \cdot \lambda^{2}}{d^{2}(N-1)+P \cdot Q \cdot \lambda^{2}}
$$

$\lambda^{2}=$ Standar Error $=1$

$\mathrm{P}=\mathrm{Q}=$ Nilai Probability $=0,5$

$\mathrm{N}=$ Populasi

$\mathrm{d}=$ Standar Deviasi $=0.05$

$\mathrm{S}=$ Jumlah sampel

Berdasarkan formula tersebut, dengan jumlah kepala keluarga 1.558, maka jumlah responden minimal yang harus diambil adalah 124 responden. Jumlah responden terdistribusi secara proporsional pada tiap desa sesuai dengan jumlah keluarga di masing-masing desa. Proporsi jumlah responden pada masingmasing desa dapat dilihat pada Tabel 1 .

Jumlah responden di Desa Mattiro Baji adalah yang terkecil diantara desa yang lainnya karena hanya terdapat satu dusun yang letaknya berada di Pulau Tanakeke, sedangkan dusun yang lain berada di luar Pulau Tanakeke. Pengambilan data primer dilakukan dengan menggunakan wawancara dan kuesioner. Wawancara juga dilakukan dengan responden kunci, yaitu tokoh

Tabel 1. Jumlah responden pada masing-masing desa Table 1. The number of respondent at each village

\begin{tabular}{llcc}
\hline No. & Desa (Village) & $\begin{array}{c}\text { Jumlah Keluarga (Number } \\
\text { offamily) }\end{array}$ & $\begin{array}{c}\text { Jumlah Responden } \\
\text { (Number of respondent) }\end{array}$ \\
\hline 1. & Maccini Baji & 298 & 24 \\
2. & Balandatu & 500 & 40 \\
3. & Tompotana & 318 & 25 \\
4. & Rewatayya & 402 & 32 \\
5. & Mattiro Baji & 40 & 3 \\
\hline
\end{tabular}

Sumber (Source): Data primer (Primary data). 2015 
masyarakat yang mempunyai pengetahuan seputar topik penelitian yang terdiri atas kepala desa, tokoh masyarakat dan tetua adat. Kuesioner terdiri dari pertanyaan terbuka dan tertutup. Pertanyaan terbuka digunakan untuk menggali informasi dari responden berkaitan persepsi masyarakat terhadap mangrove, sedangkan pertanyaan tertutup digunakan untuk mengukur tingkat persepsi dan sikap masyarakat terhadap konservasi ekosistem mangrove. Dalam pertanyaan tertutup terdapat lima pilihan jawaban, yaitu sangat setuju, setuju, ragu-ragu, tidak setuju dan sangat tidak setuju. Jawaban pada pertanyaan tertutup dianalisis dengan pendekatan kuantitatif dengan menggunakan Skala Likert (Mamuko et al., 2016).

Tingkat persepsi seseorang atau sekelompok orang dapat berbeda-beda. Menurut Mamiri (2008), tingkat persepsi masyarakat dipengaruhi oleh faktor internal dan eksternal. Faktor internal adalah nilainilai dalam diri yang dipadukan dengan halhal yang ditangkap panca indera dari proses melihat, meraba, mencium, mendengar dan merasakan. Faktor tersebut kemudian dikombinasikan dengan faktor eksternal yaitu keadaan lingkungan fisik dan sosial yang kemudian menjadi respon dalam bentuk tindakan. Pada penelitian ini, faktor intenal yang diasumsikan berpengaruh terhadap tingkat persepsi dan sikap adalah tempat tinggal, umur, gender, lama tinggal, daerah asal, tingkat pendidikan, jumlah anggota keluarga, jenis pekerjaan dan tingkat pendapatan. Faktor eksternal yang diasumsikan berpengaruh terhadap tingkat persepsi dan sikap adalah keikutsertaan responden pada kegiatan penyuluhan dan kegiatan rehabilitasi.

\section{Analisis Data}

Data hasil kuesioner selanjutnya ditabulasikan dengan menggunakan Microsoft Excel. Analisis data dilakukan dengan metode deskriptif dan analisis statistik regresi linear berganda. Analisis data secara deskriptif digunakan untuk menggambarkan kondisi daerah penelitian dan menjabarkan data hasil wawancara. Analisis statistik digunakan untuk menilai faktor-faktor yang berpengaruh terhadap tingkat persepsi dan sikap. Untuk memudahkan proses analisis statistik, sebelum proses pengolahan data terlebih dahulu dilakukan skoring pada jawaban responden dan karakteristik responden sesuai dengan hasil kuesioner. Analisis data dilakukan dengan menggunakan Software SPSS 19.

\section{HASIL DAN PEMBAHASAN}

\section{A. Kondisi Biofisik dan Karakteristik Responden}

Posisi Pulau Tanakeke berada di ujung barat daya dari daratan Pulau Sulawesi. Jarak terdekat dengan daratan di Kabupaten Takalar sekitar 3,5 km. Pulau Tanakeke mempunyai luas 43,12 $\mathrm{km}^{2}$, berdasarkan UndangUndang (UU) Nomor 27 Tahun 2007 tentang Pengelolaan Wilayah Pesisir dan Pulau Kecil, pulau dengan luasan kurang dari atau sama dengan $2.000 \mathrm{~km}^{2}$ dikategorikan sebagai pulau kecil, sedangkan berdasarkan Falkland et al. (1991), Pulau Tanakeke termasuk dalam kategori "sangat kecil" karena mempunyai ukuran tidak lebih dari $100 \mathrm{~km}^{2}$ atau lebarnya tidak lebih besar dari $3 \mathrm{~km}$. Pulau Tanakeke berbatasan dengan perairan laut, sebelah utara berbatasan dengan Selat Makassar, sebelah timur berbatasan dengan Selat Tanakeke dan Desa Takalar, sebelah selatan dan sebelah barat berbatasan dengan Selat Makassar.

Secara geomorfologi, Pulau Tanakeke terbentuk oleh terumbu karang yang terangkat ke atas permukaan karena adanya gerakan ke atas (uplift) dan gerakan ke bawah (subsidence) dari dasar laut karena proses geologi. Pada saat dasar laut berada dekat permukaan, terumbu karang mempunyai kesempatan untuk tumbuh dan berkembang di dasar laut yang naik. Setelah berada di permukaan air laut, terumbu karang akan mati dan menyisakan terumbu berbentuk pulau karang timbul. Proses ini berlangsung secara terus 
menerus hingga membentuk daratan pulau karang. Berdasarkan pengamatan di lapangan, kondisi topografi pulau ini merupakan dataran rendah dengan topografi datar dengan tingkat kelerengan $0-8 \%$. Pulau ini memiliki bentuk luar yang berlekuk-lekuk (menyerupai bentuk jari manusia), membentuk laguna dan teluk. Kondisi ini membuat hempasan angin dapat tertahan dan pesisir pantainya kaya akan endapan lumpur yang merupakan habitat yang sesuai untuk tumbuh dan berkembangnya mangrove.

Secara umum, masyarakat yang bermukim di Pulau Tanakeke adalah masyarakat asli yang yang berasal dari Suku Makassar. Mereka pada umumnya berasal dari penduduk daratan Pulau Sulawesi yang memutuskan untuk menetap secara permanen di Pulau Tanakeke. Berdasarkan hasil wawancara dengan tokoh masyarakat, nenek moyang masyarakat Pulau Tanakeke adalah orangorang buangan pemerintah kolonial Belanda yang tidak mampu membayar pajak. Kondisi perekonomian penduduk di Pulau Tanakeke secara umum masih dibawah garis kemiskinan. Seperti pada umumnya masyarakat nelayan, masyarakat menggantungkan hidupnya pada kegiatan sektor perikanan, budidaya rumput laut dan usaha-usaha lain yang dapat menopang kehidupannya.

Dari jumlah responden sebanyak 124 orang, 90\% laki-laki dan 10\% perempuan. Secara umum, hampir semua responden (98\%) merupakan masyarakat asli yang mendiami Pulau Tanakeke, sedangkan sisanya adalah masyarakat pendatang. Umur responden dibagi ke dalam tiga kelompok, yaitu kurang dari 35 tahun $23,39 \%$, antara 35 sampai 55 tahun $62,10 \%$ dan lebih dari 55 tahun $14,52 \%$. Berdasarkan penghasilan per bulan, $19 \%$ responden berpenghasilan kurang dari Rp750.000/bulan, 38\% berpenghasilan antara Rp750.000-Rp1.500.000/bulan dan 43\% mempunyai pengahasilan diatas Rp1.500.000/ bulan. Mayoritas mata pencaharian responden adalah nelayan, baik nelayan tambak maupun nelayan tangkap. Sedangkan mata pencaharian sampingannya adalah petani rumput laut dan pembuat arang.

Pendidikan yang dimaksud adalah pendidikanformalterakhiryang telah ditempuh responden sampai penelitian ini dilakukan. Berdasarkan tingkat pendidikannya, 75,81\% responden hanya sampai Sekolah Dasar (SD) atau dibawah sekolah dasar, sebesar 24,19\% responden menempuh pendidikan formal tingkat Sekolah Menengah Pertama (SMP) sampai Sekolah Menengah Atas (SMA)/ sederajat. Rendahnya tingkat pendidikan responden disebabkan pada waktu itu sekolah dasar hanya terdapat di Desa Maccini Baji, sementara akses antar desa hanya dapat dilakukan dengan perahu. Kondisi ekonomi yang lemah juga menyebabkan anak-anak usia sekolah harus membantu orang tuanya bekerja. Berdasarkan jumlah anggota keluarga, sebagian besar keluarga terdiri dari 5 sampai 7 orang $(41,13 \%)$, kurang dari 5 orang sebesar $29,84 \%$ dan $29,03 \%$ responden memiliki jumlah keluarga lebih dari 7 orang.

\section{B. Persepsi Masyarakat}

Penilaian persepsi masyarakat terhadap pengelolaan kawasan mangrove juga sangat dipengaruhi oleh tingkat pendidikan dan pengetahuan masyarakat (Nanlohy et al., 2014). Persepsi responden terhadap istilah hutan mangrove menyatakan bahwa 78,23\% responden menyatakan sudah pernah mendengar istilah hutan mangrove dan sisanya belum pernah mendengar istilah hutan mangrove. Istilah hutan mangrove sebagian besar diketahui masyarakat dari instansi pemerintah dan organisasi nonpemerintah yang pernah mengadakan kegiatan penyuluhan atau rehabilitasi kawasan pesisir di Pulau Tanakeke. Masyarakat yang tidak mengetahui istilah hutan mangrove menyebut mangrove sebagai "bangko". Sebanyak $50 \%$ responden menyatakan bahwa habitat atau tempat tumbuh hutan mangrove berada di sepanjang pantai, $22,58 \%$ responden menyatakan di sepanjang pantai dan tambak, $10,48 \%$ responden menyatakan di tepi sungai, 
4,03\% responden menyatakan di sekitar tambak, dan $12,90 \%$ responden menyatakan bahwa semua tempat tersebut adalah habitat hutan mangrove.

Persepsi responden mengenai kondisi hutan mangrove di Pulau Tanakeke, 52,42\% responden menyatakan bahwa kondisi hutan mangrove saat ini sudah mulai berkurang akibat adanya penebangan untuk pembuatan arang dan ajir rumput laut, sebanyak $28,23 \%$ responden menyatakan hutan mangrove saat ini sudah rusak dan hanya 19,35\% responden yang menyatakan kondisi hutan mangrove saat ini masih sangat bagus. Kondisi ini terutama tejadi di desa-desa yang telah dilakukan kegiatan rehabilitasi, sehingga kondisi hutan mangrove saat ini sudah lebih baik bila dibanding beberapa tahun sebelum penghijauan dilakukan, yaitu sebelum tahun 2010. Persepsi masyarakat mengenai fungsi ekologi mangrove, sebanyak $94,35 \%$ responden menyatakan mereka setuju bahwa hutan mangrove merupakan tempat berkembangnya ikan, udang dan biota laut lainnya, dan 5,65\% responden menyatakan tidak setuju. Persepsi responden terhadap manfaat yang dirasakan dengan keberadaan hutan mangrove adalah sebagai sumber mata pencaharian $(0,81 \%)$, sumber kayu bakar, arang dan ajir rumput laut (14,52\%), penahan ombak, angin dan abrasi (9,68\%), sebagai sumber mata pencaharian dan penahan ombak $(2,42 \%)$, sebagai penahan ombak dan sumber kayu ajir rumput laut $(21,77 \%)$, dan sebanyak $50,81 \%$ responden menyatakan bahwa mereka merasakan semua manfaat tersebut.

Selain memiliki fungsi ekologi, hutan mangrove juga memiliki fungsi sosialekonomi yang bermanfaat dalam menopang kehidupan ekonomi masyarakat. Fungsi sosialekonomi mangrove dapat diperoleh secara optimal dengan dukungan ilmu pengetahuan dan teknologi. Persepsi responden mengenai fungsi sosial-ekonomi hutan mangrove perlu diukur sebagai salah satu cara untuk mengetahui kontribusi sosial-ekonomi mangrove bagi kehidupan masyarakat. Hasil wawancara menyatakan bahwa nilai ekonomi hutan mangrove yang saat ini banyak dirasakan oleh responden adalah adanya alih fungsi lahan mangrove menjadi tambak, dan pembuatan arang dari kayu mangrove. Persepsi responden digunakan untuk mengetahui bagaimana pendapat mereka dengan adanya dua fenomena tersebut di sekitar lingkungan mereka. Sebanyak 94,35\% responden menyatakan setuju dan 5,65\% responden tidak setuju dengan adanya alih fungsi hutan mangrove menjadi tambak. Bagi yang setuju, mereka menyatakan bahwa dengan adanya alih fungsi lahan tersebut membuat pendapatan mereka menjadi lebih meningkat karena hasil yang diperoleh dari tambak lebih banyak daripada jika hutan mangrove tersebut tidak diolah. Responden yang tidak setuju menyatakan bahwa adanya alih fungsi lahan tersebut dapat menyebabkan kerusakan lingkungan karena dapat menyebabkan abrasi dan tidak ada lagi penahan ombak dan angin karena banyaknya tanaman mangrove yang ditebang.

Demikian halnya dengan penebangan hutan mangrove untuk dijadikan bahan baku arang, sebanyak $81,45 \%$ responden tidak setuju, $16,94 \%$ menyatakan setuju dan $1,61 \%$ raguragu. Bagi responden yang berpendapat tidak setuju, mereka menyatakan bahwa dengan adanya pembuatan arang, hutan mangrove akan ditebang habis yang menyebabkan sebagian area menjadi gundul sehingga dapat menyebabkan kerusakan lingkungan jika tidak segera ditanami ulang. Bagi yang menyatakan setuju, hal tersebut karena hutan mangrove memberikan pendapatan bagi mereka karena arang menjadi sumber mata pencaharian mereka.

Tentang persepsi responden mengenai pengelolaan hutan mangrove di Pulau Tanakeke, sebagian besar responden (94,35\%) menganggap hutan mangrove dimiliki oleh pribadi, sehingga pengelolaanya diserahkan sepenuhnya pada pemilik hutan mangrove tersebut. Sebanyak 4,84\% responden menyatakan bahwa hutan mangrove dimiliki 
oleh pemerintah dan $0,81 \%$ masih ragu-ragu tentang siapa pemilik hutan mangrove itu sebenarnya. Hutan mangrove bagi sebagian besar masyarakat Pulau Tanakeke dianggap seperti lahan kebun bagi masyarakat di daratan dan menjadi aset keluarga yang dapat diwariskan secara turun-temurun. Kepemilikan hutan mangrove sebagian besar berasal dari warisan orang tua dan sebagian yang lain dari pembelian. Kegiatan pengelolaan hutan mangrove selama ini menurut responden lebih banyak dikelola oleh masyarakat. Hal ini tidak terlepas dari persepsi sebagian besar masyarakat yang menganggap hutan mangrove dimiliki secara pribadi oleh masyarakat, sehingga pengelolaan hutan mangrove lebih banyak dilakukan oleh pemilik masing-masing.

\section{Tingkat Persepsi}

Berdasarkan hasil pengolahan data kuesioner, diketahui bahwa $18,5 \%$ responden mempunyai tingkat persepsi rendah, 41,14\% responden mempunyai tingkat persepsi sedang dan 40,3\% responden mempunyai tingkat persepsi tinggi. Dengan demikian, dominasi tingkat persepsi masyarakat sebagian besar berada pada tingkat sedang dan tinggi. Menurut Ngakan et al. (2006), persepsi dalam kategori sedang adalah apabila masyarakat telah menyadari dirinya bergantung hidup dari sumber daya hayati hutan tetapi tidak memahami kalau sumber daya tersebut perlu dikelola secara lestari agar manfaatnya bisa diperoleh secara berkelanjutan. Persepsi tinggi, apabila masyarakat memahami dengan baik bahwa dirinya bergantung hidup dari sumber daya hayati hutan dan menginginkan agar sumber daya tersebut dikelola secara lestari;

Analisis regresi linear berganda digunakan untuk mengetahui pengaruh variabel bebas terhadap variabel terikat. Variabel bebas dalam penelitian ini adalah lokasi tempat tinggal, tingkat pendidikan, kegiatan penyuluhan dan kegiatan rehabilitasi, sedangkan variabel dependen adalah tingkat persepsi masyarakat terhadap mangrove. Hasil analisis regresi linear berganda didapatka tiga buah tabel yang terdiri atas, tabel analisis korelasi ganda, tabel hasil uji $\mathrm{F}$ (Anova) dan tabel uji T. Analisis korelasi ganda ini digunakan untuk mengetahui hubungan antara dua atau lebih variabel independen terhadap variabel dependen secara serentak. Koefisien ini menunjukkan seberapa besar hubungan yang terjadi antara variabel independen secara serentak terhadap variabel dependen. Hasil analisis korelasi ganda dapat dilihat pada Tabel 2.

Dari Tabel 2 diketahui bahwa nilai $\mathrm{R}$ adalah 0,730 atau $>0,5$ yang menunjukkan hubungan antara tempat tinggal, umur, gender (jenis kelamin), lama tinggal, daerah asal, pendidikan, jumlah keluarga, pekerjaan, tingkat pendapatan, kegiatan penyuluhan, kegiatan rehabilitasi terhadap tingkat persepsi secara serentak termasuk dalam kategori kuat $(\mathrm{R}>0,5)$. Hasil uji koefisien regresi tingkat persepsi disajikan pada Tabel 3.

Tabel 2. Hasil analisis korelasi ganda tingkat persepsi menggunakan analisis regresi linear berganda

Table 2. The result of multiple correlation analysis of perception levels using multiple linear regression analysis

Model Summary ${ }^{\mathrm{b}}$

\begin{tabular}{|c|c|c|c|c|}
\hline Model & $\mathrm{R}$ & R Square & $\begin{array}{l}\text { Adjusted R } \\
\text { Square }\end{array}$ & Std. Error of the Estimate \\
\hline 1 & $0,730^{\mathrm{a}}$ & 0,533 & 0,487 & 0,52930 \\
\hline \multicolumn{5}{|c|}{$\begin{array}{l}\text { a. Predictors: (Constant), Keg_Rehabilitasi, Tempat_tinggal, Pekerjaan, Gender, Umur, } \\
\text { Pendapatan, Asal, Jumlah_Keluarga, Lama_Tinggal, Pendidikan, Keg_Penyuluhan }\end{array}$} \\
\hline \multicolumn{5}{|c|}{ b. Dependent Variable: Persepsi } \\
\hline
\end{tabular}


Tabel 3. Hasil uji anova tingkat persepsi menggunakan analisis regresi linear berganda

Table 3. The result of anova test of people perception levels using multiple linear regression analysis

ANOVA $^{\mathrm{a}}$

\begin{tabular}{|c|c|c|c|c|c|c|}
\hline & Model & Sum of Squares & $\mathrm{df}$ & Mean Square & $\mathrm{F}$ & Sig. \\
\hline \multirow[t]{3}{*}{1} & Regression & 35,743 & 11 & 3,249 & 11,598 & $0,000^{\mathrm{b}}$ \\
\hline & Residual & 31,378 & 112 & 0,280 & & \\
\hline & Total & 67,121 & 123 & & & \\
\hline
\end{tabular}

a. Dependent Variable: Persepsi

b. Predictors: (Constant), Keg_Rehabilitasi, Tempat_tinggal, Pekerjaan, Gender, Umur, Pendapatan, Asal, Jumlah_Keluarga, Lama_Tinggal, Pendidikan, Keg_Penyuluhan

Sumber (Source): Analisis data primer (Primary data analysis)

Berdasarkan Tabel 3 diperoleh nilai $\mathrm{F}$ hitung sebesar 11,598. Nilai $F$ tabel dapat diperoleh dengan menggunakan tabel $\mathrm{F}$ dengan derajat bebas (df) Residual yaitu 112 dengan taraf siginifikan 0,05 (tingkat keyakinan 95\%), sehingga diperoleh nilai $\mathrm{F}$ tabel sebesar 1,875. Karena F hitung $(11,598)$ $>\mathrm{F}$ tabel $(1,875)$ artinya terdapat pengaruh yang signifikan antara tempat tinggal, umur, gender, lama tinggal, daerah asal, pendidikan, jumlah keluarga, pekerjaan, tingkat pendapatan, kegiatan penyuluhan, kegiatan rehabilitasi secara bersama-sama terhadap tingkat persepsi. Hal ini juga berarti model regresi yang dihasilkan dapat digunakan untuk memprediksi variabel dependen. Hasil uji koefisien regresi secara parsial (uji t) tingkat persepsi disajikan pada Tabel 4.

Nilai $t$ tabel dapat diperoleh dengan menggunakan tabel $\mathrm{t}$ dengan derajat bebas 112 dan taraf signifikansi $0,05(\alpha$ 5\%) adalah 1,981. Berdasarkan data $t$ hitung yang terdapat pada Tabel 4 diperoleh hasil analisis, terdapat tiga variabel bebas yang mempunyai nilai thitung lebih besar dari pada $t$ tabel, atau nilai signifikansi ( $\mathrm{p}$ value) dibawah 0,05 yaitu variabel tempat tinggal responden, tingkat pendidikan dan keikutsertaan responden dalam kegiatan rehabilitasi mangrove. Ketiga variabel tersebut yang secara parsial berpengaruh signifikan terhadap tingkat persepsi masyarakat. Hasil ini dikuatkan oleh penelitian Diarto et al. (2012) yang menyatakan, tingkat pendidikan dapat

Tabel 4. Hasil uji t tingkat persepsi menggunakan analisis regresi linear berganda

Table 4. The result of t-test of people perception levels using multiple linear regression analysis

Coefficients $^{\mathrm{a}}$

\begin{tabular}{|c|c|c|c|c|c|}
\hline \multirow[t]{2}{*}{ Model } & \multicolumn{2}{|c|}{ Unstandardized Coefficients } & \multirow{2}{*}{$\frac{\text { Standardized Coefficients }}{\text { Beta }}$} & \multirow[t]{2}{*}{$\mathrm{t}$} & \multirow[t]{2}{*}{ Sig. } \\
\hline & $\mathrm{B}$ & Std. Error & & & \\
\hline 1 (Constant) & 0,467 & 0,711 & & 0,657 & 0,513 \\
\hline Tempat tinggal & 0,181 & 0,046 & 0,280 & 3,912 & $0,000 *$ \\
\hline Umur & 0,051 & 0,092 & 0,042 & 0,553 & 0,581 \\
\hline Gender & $-0,356$ & 0,184 & $-0,148$ & $-1,938$ & 0,055 \\
\hline Lama_Tinggal & $-0,051$ & 0,094 & $-0,044$ & $-0,547$ & 0,586 \\
\hline Asal & 0,336 & 0,345 & 0,070 & 0,976 & 0,331 \\
\hline Pendidikan & 0,489 & 0,144 & 0,285 & 3,405 & $0,001 *$ \\
\hline Jumlah_Keluarga & $-0,071$ & 0,070 & $-0,077$ & $-1,009$ & 0,315 \\
\hline Pekerjaan & 0,084 & 0,265 & 0,022 & 0,317 & 0,752 \\
\hline Pendapatan & $-0,094$ & 0,072 & $-0,096$ & $-1,307$ & 0,194 \\
\hline Keg_Penyuluhan & 0,113 & 0,090 & 0,122 & 1,251 & 0,213 \\
\hline Keg_Rehabilitasi & 0,347 & 0,083 & 0,392 & 4,170 & $0,000 *$ \\
\hline
\end{tabular}

a. Dependent Variable: Persepsi

Sumber (Source): Analisis data primer (Primary data analysis) 
memengaruhi bentuk persepsi masyarakat. Hasil penelitian Jumnongsong et al. (2015) menunjukkan bahwa persepsi masyarakat nelayan terhadap mangrove dipengaruhi oleh faktor tempat tinggal dan keikutsertaan pada kegiatan penyuluhan yang terkait mangrove. Hasil yang agak berbeda dikemukakan oleh Paletto et al. (2013) yang menyatakan bahwa persepsi masyarakat terhadap pengelolaan hutan dipengaruhi oleh faktor umur, jenis kelamin (gender) dan tempat tinggal. benda dan mengandung penilaian setuju tidak setuju atau suka - tidak suka (Sarwono, 2002).

Berdasarkan hasil analisis data, diketahui bahwa $8,9 \%$ responden mempunyai tingkat sikap rendah, 25,8\% responden mempunyai tingkat sikap sedang dan $65,3 \%$ responden mempunyai tingkat sikap tinggi. Dengan tingkat sikap yang didominasi pada tingkat tinggi, maka dapat dikatakan bahwa secara umum masyarakat telah memiliki sikap yang mendukung upaya konservasi mangrove di Pulau Tanakeke. Hasil analisis korelasi ganda dapat dilihat pada Tabel 5 .

Tabel 5. Hasil analisis korelasi ganda tingkat sikap menggunakan analisis regresi linear berganda

Table 5. The result of multiple correlation analysis of attitude levels using multiple linear regression analysiss

Model Summary

\begin{tabular}{ccccc}
\hline Model & R & R Square & Adjusted R Square & Std. Error of the Estimate \\
\hline 1 & $0,535^{\mathrm{a}}$ & 0,286 & 0,216 & 0,57827 \\
\hline
\end{tabular}

a. Predictors: (Constant), Keg_Rehabilitasi, Tempat_tinggal, Pekerjaan, Gender, Umur,

Pendapatan, Asal, Jumlah_Keluarga, Lama_Tinggal, Pendidikan, Keg_Penyuluhan

b. Dependent Variable: Sikap

Sumber (Source): Analisis data primer (Primary data analysis)

\section{Sikap Masyarakat}

Menurut Wawan dan Dewi (2010), sikap adalah merupakan predisposisi untuk melakukan atau tidak melakukan suatu perilaku tertentu, sikap lebih pada suatu proses kesadaran yang sifatnya individual. Sikap juga diartikan sebagai suatu kecenderungan untuk secara konsisten memberikan tanggapan menyenangkan atau tidak menyenangkan terhadap suatu objek, kecenderungan ini merupakan hasil belajar, bukan pembawaan atau keturunan. Sikap dapat bersifat positif dan dapat pula bersifat negatif. Dalam bersikap positif kecenderungan tindakan adalah mendekati, menyenangi, mengharapkan objek tertentu, sedangkan dalam sikap negatif terdapat kecenderungan untuk menjauhi, menghindari, membenci dan tidak menyukai objek tertentu. Ciri khas dari sikap adalah mempunyai objek tertentu seperti orang, perilaku, konsep, situasi, dan
Dari Tabel 5. diketahui bahwa nilai R adalah 0,535 yang menunjukkan hubungan antara tempat tinggal, umur, gender (jenis kelamin), lama tinggal, daerah asal, pendidikan, jumlah keluarga, pekerjaan, tingkat pendapatan, kegiatan penyuluhan, kegiatan rehabilitasi terhadap tingkat sikap secara bersama-sama termasuk dalam kategori kuat $(\mathrm{R}>0,5)$. Hasil uji koefisien regresi tingkat sikap disajikan Tabel 6.

Berdasarkan tabel anova atau $\mathrm{F}$ test, diperoleh nilai $\mathrm{F}$ hitung sebesar 4,087. Nilai $\mathrm{F}$ tabel dapat diperoleh dengan menggunakan tabel $\mathrm{F}$ dengan derajat bebas (df) Residual (sisa) yaitu 112 sebagai df penyebut dan df Regression (perlakuan) yaitu 11 sebagai df pembilang dengan taraf siginifikan 0,05 (tingkat keyakinan 95\%), sehingga diperoleh nilai $\mathrm{F}$ tabel sebesar 1,875 . Karena $\mathrm{F}$ hitung $(4,087)>$ F tabel $(1,875)$ artinya kesebelas variabel independen secara simultan dan 
Tabel 6. Hasil uji anova tingkat sikap menggunakan analisis regresi linear berganda

Table 6. The Result of anova test of people attitude levels using multiple linear regression analysis

ANOVA $^{\mathrm{a}}$

\begin{tabular}{llrrrrr}
\hline & Model & Sum of Squares & df & Mean Square & F & Sig. \\
\hline 1 & Regression & 15,032 & 11 & 1,367 & 4,087 & $0,000^{\mathrm{b}}$ \\
& Residual & 37,452 & 112 & 0,334 & & \\
& Total & 52,484 & 123 & & & \\
\hline
\end{tabular}

a. Dependent Variable: Sikap

b. Predictors: (Constant), Keg_Rehabilitasi, Desa, Pekerjaan, Gender, Umur, Pendapatan,

Asal, Jumlah_Keluarga, Lama_Tinggal, Pendidikan, Keg_Penyuluhan

Sumber (Source): Analisis data primer (Primary data analysis)

bersama-sama berpengaruh signifikan terdapat satu variabel bebas yang mempunyai terhadap tingkat sikap masyarakat terhadap nilai t hitung lebih besar dari pada $t$ tabel, konservasi ekosistem mangrove. Uji koefisien atau nilai signifikansi ( $\mathrm{p}$ value) dibawah regresi secara parsial (Uji t) digunakan 0,05 yaitu variabel keikutsertaan responden untuk mengetahui apakah dalam model dalam kegiatan rehabilitasi mangrove. Hanya regresi variabel independen secara parsial terdapat satu variabel eksternal yang secara berpengaruh signifikan terhadap variabel parsial berpengaruh signifikan terhadap dependen. Hasil uji koefisien regresi secara tingkat persepsi masyarakat yaitu variabel parsial (uji t) tingkat sikap disajikan pada keikutsertaan responden dalam kegiatan Tabel 7.

Nilai $\mathrm{t}$ tabel dapat diperoleh dengan menggunakan tabel $\mathrm{t}$ dengan derajat bebas 112 dan taraf signifikansi $0,05(\alpha$ 5\%) adalah 1,981. Berdasarkan data $t$ hitung yang terdapat pada Tabel 3 diperoleh hasil analisis, rehabilitasi mangrove. Berdasarkan data pada Tabel 7 diketahui bahwa jenis kelamin tidak berpengaruh terhadap tingkat sikap. Hal ini senada dengan penelitian Saputro (2013), yang menyatakan bahwa jenis kelamin tidak memengaruhi sikap masyarakat terhadap

Tabel 7. Hasil uji t tingkat sikap menggunakan analisis regresi linear berganda

Table 7. The result of t-test of people attitude levels using multiple linear regression analysis

Coefficients $^{\mathrm{a}}$

\begin{tabular}{|c|c|c|c|c|c|}
\hline \multirow[t]{2}{*}{ Model } & \multicolumn{2}{|c|}{$\begin{array}{l}\text { Unstandardized } \\
\text { Coefficients }\end{array}$} & Standardized Coefficients & \multirow[t]{2}{*}{$\mathrm{t}$} & \multirow[t]{2}{*}{ Sig. } \\
\hline & B & Std. Error & Beta & & \\
\hline 1 (Constant $)$ & 0,489 & 0,776 & & 0,629 & 0,530 \\
\hline Desa & 0,075 & 0,051 & 0,132 & 1,487 & 0,140 \\
\hline Umur & $-0,054$ & 0,101 & $-0,050$ & $-0,533$ & 0,595 \\
\hline Gender & $-0,275$ & 0,201 & $-0,130$ & $-1,374$ & 0,172 \\
\hline Lama_Tinggal & 0,114 & 0,103 & 0,111 & 1,112 & 0,269 \\
\hline Asal & 0,567 & 0,377 & 0,134 & 1,507 & 0,135 \\
\hline Pendidikan & 0,123 & 0,157 & 0,081 & 0,783 & 0,435 \\
\hline Jumlah_Keluarga & 0,120 & 0,076 & 0,148 & 1,575 & 0,118 \\
\hline Pekerjaan & 0,185 & 0,289 & 0,056 & 0,640 & 0,524 \\
\hline Pendapatan & 0,128 & 0,079 & 0,149 & 1,634 & 0,105 \\
\hline Keg_Penyuluhan & $-0,127$ & 0,098 & $-0,156$ & $-1,291$ & 0,199 \\
\hline Keg_Rehabilitasi & 0,290 & 0,091 & 0,372 & 3,196 & $0,002^{*}$ \\
\hline
\end{tabular}

Sumber (Source): Analisis data primer (Primary data analysis) 
pengelolaan hutan kota Srengseng di Jakarta Barat. Hasil penelitian Hakim (2014), menyatakan bahwa faktor umur, jumlah anggota keluarga, pendidikan, pekerjaan, jenis kelamin dan keikutsertaan pada kegiatan penyuluhan tidak memengaruhi sikap masyarakat terhadap pengelolaan hutan mangrove di Kelurahan Wonorejo, Kota Surabaya. Sementara itu hasil penelitian Ruchi et al. (2012) menyatakan bahwa faktor demografi dan kondisi sosial ekonomi masyarakat berpengaruh terhadap sikap masyakat dalam konservasi mangrove.

\section{KESIMPULAN DAN SARAN}

\section{A. Kesimpulan}

Ekosistem mangrove di Pulau Tanakeke, Kabupaten Takalar, Provinsi Sulawesi Selatan mempunyai peranan yang sangat penting baik dari segi fisik, ekologi maupun ekonomi. Ketergantungan masyarakat terhadap ekosistem mangrove sangat tinggi, utamanya dalam menopang kehidupan ekonominya. Tingginya ketergantungan tersebut menyebabkan tingkat eksploitasi mangrove semakin tinggi, akibatnya laju degradasi mangrove di kawasan ini semakin meningkat. Kondisi ini jika dibiarkan secara terusmenerus akan berakibat semakin menurunnya kehidupan ekonomi masyarakat. Berbagai upaya konservasi mangrove telah dilakukan di kawasan ini, tetapi hasilnya kurang begitu optimal. Penilaian persepsi dan sikap masyarakat terhadap ekosistem mangrove akan memengaruhi dukungannya terhadap keberhasilan upaya konservasi mangrove di Pulau Tanakeke. Persepsi dan sikap masyarakat ini dapat diketahui dengan melihat bagaimana masyarakat memperlakukan hutan mangrove agar lestari dan bermanfaat secara berkelanjutan. Persepsi masyarakat yang tinggi ditandai dengan pemahaman yang baik bahwa kehidupannya sangat bergantung dari sumber daya hayati ekosistem mangrove dan menginginkan agar sumber daya tersebut dikelola secara lestari, sedangkan sikap yang tinggi berarti masyarakat sangat mendukung kegiatan konservasi ekosistem mangrove. Tingkat persepsi masyarakat sangat dipengaruhi oleh faktor tempat tinggal, pendidikan dan keikutsertaan masyarakat dalam kegiatan rehabilitasi mangrove, sedangkan tingkat sikap masyarakat sangat dipengaruhi oleh keikutsertaannya dalam kegiatan rehabilitasi mangrove.

\section{B. Saran}

Upaya konservasi ekosistem mangrove di Pulau Tanakeke yang dilakukan, baik oleh pemerintah maupun organisasi nonpemerintah, seringkali hasilnya tidak optimal. Salah satu penyebabnya adalah adanya persepsi yang berkembang di sebagian besar masyarakat yang menganggap bahwa kawasan mangrove di Pulau Tanaekek dimiliki oleh pribadi, dan dianggap sebagai aset kekayaan yang bernilai ekonomi tinggi. Tingginya nilai mangrove tersebut dikarenakan besarnya permintaan kayu mangrove dari industri arang. Untuk meningkatkan keberhasilan upaya konservai tersebut, pemerintah maupun organisasi non-pemerintah perlu melakukan sosialisasi dan penyuluhan secara intensif terkait kepemilikan mangrove tersebut.

\section{UCAPAN TERIMA KASIH}

Terimakasih disampaikan kepada Balai Penelitian dan Pengembangan Lingkungan Hidup dan Kehutanan Makassar yang telah memberikan dukungan dana sehingga kegiatan penelitian ini dapat terwujud. Ucapan terimakasih juga kami sampaikan kepada masyarakat Pulau Tanakeke, tokoh masyarakat dan pihak-pihak yang telah membantu selama kami melaksanakan kegiatan di Pulau Tanakeke. Tidak lupa kami sampaikan ucapan terimakasih kepada Sdr. Arman Hermawan yang telah membantu dalam kegiatan pengambilan data di lapangan. 


\section{DAFTAR PUSTAKA}

Akbar, M. (2014). Geospatial modeling of vegetation cover changes on a small island (Case study: Tanakeke Island, Takalar District, South Sulawesi). (Tesis). Bogor: Bogor Agricultural University.

Beys-da-Silva, W. O., Santi, L. and Guimarães, J. A. (2014). Mangroves: A Threatened ecosystem under-utilized as a resource for scientific research. Journal of Sustainable Development, $7(5), \quad 40-51 . \quad$ http://doi.org/10.5539/jsd. v7n5p40

Blanco, J. F., Estrada, E. a., Ortiz, L. F. and Urrego, L. E. (2012). Ecosystem-wide impacts of deforestation in mangroves: The Urabá Gulf (Colombian Caribbean) case study. ISRN Ecology, 2012, 1-14. http://doi. org/10.5402/2012/958709

Diarto, Hendrarto, B. dan Suryoko, S. (2012). Partisipasi mayarakat dalam pengelolaan lingkungan kawasan hutan mangrove Tugurejo di Kota Semarang. Jurnal Ilmu Lingkungan, 10(1), 1-7.

Dolisca, F., McDaniel, J. M. and Teeter, L. D. (2007). Farmers' perceptions towards forests: A case study from Haiti. Forest Policy \& Economics, 9(6), 704-712.

Falkland, A. C., Custodio, E., Diaz Arenas, A. and Simler, L. (1991). Hydrology and water resources of small islands : a practical guide. Studies and reports in hydrology (Vol. 49).

Giri, C., Ochieng, E., Tieszen, L. L., Zhu, Z., Singh, A., Loveland, T., Masek, J. and Duke, N. (2011). Status and distribution of mangrove forests of the world using earth. Global Ecology and Biogeography, 20, 154-159. http://doi. org/10.1111/j.1466-8238.2010.00584.x

Hakim, A. M. (2014). Persepsi, sikap dan partisipasi masyarakat sekitar dalam pengelolaan hutan mangrove di Wonorejo, Surabaya. (Skripsi). Bogor: Institut Pertanian Bogor.

Hussain, S. A. and Badola, R. (2010). Valuing mangrove benefits: Contribution of mangrove forests to local livelihoods in Bhitarkanika Conservation Area, East Coast of India. Wetlands Ecology and Management, 18(3), 321-331. http://doi.org/10.1007/s11273-0099173-3

Jumnongsong, S., Gallardo, W. G., Ikejima, K.. and Cochard, R. (2015). Factors affecting fishers' perceptions of benefits, threats, and state, and participation in mangrove management in Pak Phanang Bay, Thailand. Journal of Coastal Research, 31(1), 95-106. http://doi. org/10.2112/JCOASTRES-D-12-00257.1

Lee, H. F. and Zhang, D. D. (2008). Perceiving the environment from the lay perspective in desertified areas, northern China. Environmental Management, 41(2), 168-182. http://doi.org/10.1007/s00267-007-9052-8

Mamiri, S. A. (2008). Persepsi dan preferensi pengunjung terhadap fungsi dan lokasi obyek-obyek rekreasi di Kebun Raya Bogor.
(Skripsi). Bogor: Institut Pertanian Bogor.

Mamuko, F., Walangitan, H. dan Tilaar, W. (2016). Persepsi dan partisipasi masyarakat dalam upaya rehabilitasi hutan dan lahan di Kabupaten Bolaang Mongondow Timur. Eugenia, 22(2), 80-92.

Nanlohy, H., Bambang, A. N., Ambaryanto. dan Hutabarat, S. (2014). Analisis persepsi masyarakat terhadap pengelolaan kawasan mangrove Teluk Kotania. Jurnal Wilayah dan Lingkungan, 2(1), 89-98.

Ngakan, P. O., Komarudin, H., Achmad, A., Wahyudi. dan Tako, A. (2006). Ketergantungan, persepsi dan partisipasi masyarakat terhadap sumber daya hayati hutan (Studi Kasus di Dusun Pampli Kabupaten Luwu Utara, Sulawesi Selatan). Bogor: Center for International Forestry Research.

Pahlevi, T. (2007). Persepsi masyarakat terhadap Taman Wisata Alam Sicikeh-Cikeh (Studi Kasus di Dusun Pancur Nauli, Desa Lae Hole II, Kec. Parbuluan, Kab. Dairi, Sumatera Utara). (Skripsi). Universitas Sumatera Utara.

Paletto, A., De Meo, I., Cantiani, M. G.. and Maino, F. (2013). Social perceptions and forest management strategies in An Italian Alpine community. Mountain Research and Development, 33(2), 152-160. http://doi. org/10.1659/MRD-JOURNAL-D-12-00115.1

Pontoh, O.(2011). Peranan nelayan terhadap rehabilitasi ekosistem hutan bakau (mangrove). Jurnal Perikanan dan Kelautan Tropis, VII(2), 7379.

Rahayu, W. M. (2010). Persepsi, sikap dan perilaku masyarakat terhadap kelestarian hutan (Studi kasus di Desa Cinagara dan Desa Pasir Buncir Kecamatan Caringin, Kabupaten Bogor, Jawa Barat). (Skripsi). Bogor: Institut Pertanian Bogor.

Ruchi, B., Shivani, B. and Ainul, H. S. (2012). Attitudes of local communities towards conservation of mangrove forests: A case study from the east coast of India. Estuarine, Coastal and Shelf Science, 96, 188-196. http://doi. org/10.1016/j.ecss.2011.11.016

Saputro, T. S. (2013). Persepsi, sikap, dan partisipasi masyarakat sekitar terhadap pengelolaan hutan kota Srengseng, Jakarta Barat menurut perspektif gender. (Skripsi). Bogor: Institut Pertanian Bogor.

Sarwono, S. W. (2002). Psikologi sosial: Individu dan teori-teori psikologi sosial. Jakarta: Balai Pustaka.

Soukotta, L. M. (2013). Valuasi ekonomi ekosistem hutan mangrove di Negeri Tawiri Kota Ambon. Jurnal Ilmu Pengetahuan dan Teknologi, 25(1), 1-7.

Souza, F. E. S. and Augusto, C. (2011). Ecological and economic valuation of the potengi estuary mangrove wetlands (NE, Brazil) using ancillary spatial data. Journal of Coastal Conservation, 15, 195-206. http://doi. org/10.1007/s11852-010-0133-0 
Sugiyono. (2009). Metode penelitian kuantitatifkualitatif dan research development. Bandung: Alfabeta.

Talakua, W. (2013). Valuasi Ekonomi ekosistem hutan mangrove di Negeri Passo Kota Ambon. Jurnal Ilmu Pengetahuan Dan Teknologi, 25(1), 8-14.

Tumisem, dan Suwarno. (2008). Degradasi hutan bakau akibat pengambilan kayu bakar oleh indutri kecil gula kelapa di Cilacap. Jurnal Forum Geograf, 22(2), 159-168.

Uddin, M. S., de Ruyter van Steveninck, E., Stuip, M. and Shah, M. A. R. (2013). Economic valuation of provisioning and cultural services of a protected mangrove ecosystem: A case study on Sundarbans Reserve Forest, Bangladesh. Ecosystem Services, 5(October
2014), 88-93. http://doi.org/10.1016/j. ecoser.2013.07.002

Ushakiranmai, G., and Rajasekhar, P. S. (2015). A study on habitat loss of mangrove swamps / salt marshes over a period in Visakhapatnam Urban Environment, Andhra Pradesh, India. Universal Journal of Environmetal Research and Technology, 5(4), 173-178.

Wawan, dan Dewi. (2010). Teori dan pengukuran pengetahuan, sikap dan perilaku manusia. Yogyakarta: Nuha Medika.

Yuliasamaya, Darmawan, A. dan Hilmanto, R. (2014). Perubahan tutupan hutan mangrove di pesisir Kabupaten Lampung Timur. Jurnal Sylva Lestari, 2(3), 111-124. 